\title{
Epstein-Barr virus gene expression in human breast cancer: protagonist or passenger?
}

\author{
SA Xue ${ }^{1,2}$, IA Lampert ${ }^{3}$, JS Haldane ${ }^{4}$, JE Bridger ${ }^{4,5}$ and BE Griffin ${ }^{*, 1}$ \\ 'Viral Oncology Unit, Division of Medicine, Imperial College Faculty of Medicine at St Mary's, Norfolk Place, London W2 IPG, UK; ' ${ }^{2}$ College of Life \\ Sciences, Shaanxi Normal University, Xian 7 10062, People's Republic of China; ${ }^{3}$ Department of Histopathology, Hammersmith Hospital, Du Cane Road, \\ London WI 2 ONN, UK; ${ }^{4}$ Department of Histopathology, New Cross Hospital, Wolverhampton, UK
}

\begin{abstract}
The presence and transcriptional expression of Epstein-Barr virus (EBV)-encoded genes, oestrogen receptor (ER) status and degree of lymphocyte infiltration were evaluated in 15 mastectomy-removed breast cancer samples, mostly of ductal origin. With regard to these parameters, the tumours were heterogeneous. Viral genes, including EBNAI - a universal EBV marker - and others, selected in part on the basis of expression in other EBV-associated carcinomas and/or presence in an epithelial cell immortalising subfragment p3I of viral DNA, were detected in up to $40 \%$ of the breast malignancies. The small viral RNAs, EBERs, were not observed. In culture, p3I EBV DNA, alone among EBV fragments, stimulated the growth of human breast-milk epithelial cells. There was no correlation between viral and ER expression and tumours were heterogeneous with regard to their invasive lymphocytes: of three studied in detail, one contained none, another had (mainly) T-lymphocyte aggregates on the tumour periphery, and a third (BC I2) was infiltrated with both $\mathrm{T}$ - and B-lymphocytes. BC 12 differed in several aspects from other malignancies in expressing a transcriptional activator (BZLFI) associated with overcoming virus latency, and failing to express a viral oncogene, BARFI. Arguments are given for EBV as a protagonist cocarcinogen in some breast malignancies.

British Journal of Cancer (2003) 89, I I3- I 19. doi: I 0.1038/sj.bjc.660 I027 www.bjcancer.com
\end{abstract}

(C) 2003 Cancer Research UK

Keywords: breast carcinoma; EBV gene expression; invasive lymphocytes; oestrogen receptor; p3। EBV DNA

Breast cancer is well-recognised as a heterogeneous condition and a major cause of death among women. About 800000 new cases per year are reported worldwide, with one in 11 women estimated to develop this malignancy. In developed countries, $>200$ cases per 100000 women per year are seen, $10-15 \%$ of these coming from families with a previous history of breast carcinoma (Parkin et al, 1999). Breast cancer susceptibility genes, including BRCA 1 and 2 (found on chromosomes-17 and -3), exist, adding support for genetic predisposition for some forms of this malignancy (Masood and Kameh, 2002). Late exposure to a common virus, such as human cytomegalovirus, has been suggested as a risk factor for breast carcinomas (Richardson, 1997), and Yasui et al (2001) argue that delayed infection with Epstein-Barr virus (EBV) may also be a risk for this malignancy. For EBV, there is evidence for its presence and expression in subpopulations (up to 50\%, but frequently less) of breast tumours (Labrecque et al, 1995; Luqmani and Shousha, 1995; Bonnet et al, 1999; Joab, 2000; Fina et al, 2001; Grinstein et al, 2002; Kleer et al, 2002; see the discussion by Magrath and Bhatia, 1999). Data that illustrate direct entry of this virus into epithelial cells by routes involving an epithelial-specific receptor (Sixbey et al, 1987; Yoshiyama et al, 1997) or cell-cell

\footnotetext{
* Correspondence: Professor BE Griffin, Viral Oncology Unit, Division of Medicine, Imperial College at St Mary's, Norfolk Place, London W2 IPG, UK; E-mail: b.griffin@imperial.ac.uk

${ }^{5}$ Current address: Department of Histopathology, Torbay Hospital, Torquay, Devon TQ27AA, UK

Received 3 January 2003; revised 20 March 2003; accepted 25 March 2003
}

contact with infected lymphocytes (Bayliss and Wolf, 1980; Speck and Longnecker, 2000) have been put forward. In one breast cancer study, the presence of the virus appeared to be associated with a more malignant phenotype of the tumour (Bonnet et al, 1999).

In another instance, that of gastric carcinoma, where EBV appears to be associated with a subpopulation ( $10 \%$ or so) of the tumours, virus presence and expression was found only in the epithelial cell population (Galetsky et al, 1997). In culture, EBV has been shown to encode genes capable of growth stimulating (immortalising) epithelial populations in tissue explants (Griffin and Karran, 1984; Karran et al, 1990) by a mechanism associated with telomere survival and ablation of cell senescence (Gao et al, 2002). Based on its well-recognised ability to stimulate cell growth, and the ubiquitous appearance of this virus in the human population, it should perhaps not be surprising to find EBV as a contributing factor to initiation or growth of carcinomas other than those - notably the head and neck tumour of poorly differentiated epithelial cells, nasopharyngeal carcinoma (NPC) classically associated with it (IARC, 1997).

Whereas with NPC, EBV has been found to be present and expressed in $100 \%$ of the tumours, why only a subset of them appear to have a viral association is a question that arises with regard to breast and gastric carcinomas. Arguably, the latter tumours may be more heterogeneous than NPC. Alternatively, failure of detection of the virus may reflect low viral loads in the case of the breast and gastric malignancies, particularly from economically affluent parts of the world, as compared with high viral loads in NPCs, generally from less affluent populations. Further, the role of the virus in malignancy, as exemplified by 
retention and gene expression, may differ in the one case (NPC) from that in the others. In this study, we were attempting to answer some of these problems as they apply to breast cancer, by readdressing the question of EBV gene expression in a sample of tumours taken by mastectomy from patients in a single British hospital, over a short period of time, thus minimising other factors (environment, diet, viral strains, etc.) that might also contribute to the malignancy. Our data show interesting variations among the tumours, some of which might be harnessed for therapeutic purposes.

\section{MATERIALS AND METHODS}

\section{Patients}

Seventeen tumour biopsy samples were collected, in accordance with and approval of the local ethics committee, from patients presenting with suspected breast malignancy to New Cross Hospital, Wolverhampton, UK, in 1997. Fifteen of these (BCs $1-8,10-13$ and 15-17) were confirmed as breast carcinomas and two, BCs 9 and 14, not confirmed as such but rather identified as a cervical lymphadenopathy and a Hodgkin's disease (HD) tumour, respectively, were used here as controls. Of the breast carcinomas, 12 were ductal in origin, either grades I (BC 3), II (BCs $1,5,6,11$, 12 and 17) or III (BCs 7, 8, 10, 13 and 16). Of the others, BC 2 was a poorly differentiated anaplastic lobular cancer (probably grade III), BC 4 (grade III) showed lobular differentiation but with ductal elements, and BC 15 (grade I) was a tubulo-lobular carcinoma. Seven out of 15 of the breast cancers (BCs 3-6, 11, 12 and 15) were oestrogen receptor (ER) positive and the others were negative. The median patient age was 62 years. BC 9, the cervical lymphadenopathy, was designated as 'possibly of viral origin', and BC 14, a nodular sclerosing HD, had high numbers of Reed Sternberg cells. For molecular analyses, fresh biopsies were transported on dry ice to the site of analysis, and stored at $-70^{\circ} \mathrm{C}$. For histochemical analyses, paraffin blocks were kept at $-20^{\circ} \mathrm{C}$. Other controls used for this study included a North African NPC (C15) passaged as a xenograft in nude mice and containing 30 copies of the EBV genome (Busson et al, 1988), a primary African Burkitt's lymphoma (from Xue et al, 2002), Asian NPCs (from Hong Kong) and numerous EBV-carrying lymphocyte cell lines.

\section{Growth stimulus of human epithelial cells in vitro}

Fragments covering the whole of the EBV genome from the transforming B95-8 strain of virus were transfected in culture into confluent layers of cells derived from human breast milk by a standard protocol (Karran et al 1990), and they were left to grow or senesce. In each case, using duplicate cultures, survival of cells over time was visualised by staining with Leishman's reagent. Growth stimulus was obtained with one subgenomic fragment, p31 DNA. As indicated elsewhere (Gao et al, 2002), this $40 \mathrm{kbp}$ component of EBV DNA includes among its genes those encoding CST/BART transcripts, which to date have been identified in all EBV-positive tumours (reviewed in Smith, 2001), and an oncogene, BARF1, with functional homology to human colony-stimulating factor (CSF) receptor (Strockbine et al, 1998), a product of the proto-oncogene, c-fms. Both CST/BARTs and BARF1 are expressed in EBV-positive nasopharyngeal (Hitt et al, 1989) and gastric (Zur Hausen et al, 2000 ) carcinomas.

\section{Expression of EBV genes}

Viral markers chosen for examination in this study (Figure 2 and legend) include the small EBV RNAs (EBERs 1 and 2) frequently used in searches for EBV (Labrecque et al, 1995; Brink et al, 2000), the EBV nuclear antigen, EBNA1, responsible for viral maintenance and found expressed in most or all virally associated tumours (IARC, 1997), and a variety of other genes associated with expression in NPC (Hitt et al, 1989; Xue et al, 2000), or associated with epithelial cell immortalisation in culture (Griffin and Karran, 1984; Karran et al, 1990) or, alternatively, thought to be B-cell specific (Xue et al, 2000, 2002).

\section{Isolation and amplification of viral DNA and RNA}

RNA was extracted from fresh frozen tumours, or cells, and purified as a pellet, using a standard guanidinium-caesium chloride method, as described (Xue et al, 2000). DNA was recovered by dialysing the supernatant from RNA preparations. For analyses by polymerase chain reaction (PCR for DNA) or reverse transcriptase PCR (RT-PCR, for RNA), primers and probes described previously (Xue et al, 2002) were generally adopted. For EBER1 and EBER2, the primer pairs used, respectively, were (forward) 5'-AGGACCTACGCTGCCCTAGA and 5'-AAAACATGCGGACCACCAGC, and (reverse) 5'-CCCTAGTGGTTTCGGACACAC and 5'-GACAAGCCGAATACCCTTCTC. Products were confirmed by using as probes radiolabelled $5^{\prime}$ GTTTTGCTAGGGAGGAGACG (for EBER1) and 5'-GCTCCGGGGGAGGAGAAGAGAG (for EBER2). For the CST/BARTs, the forward and reverse primers were $5^{\prime}$-TGCGCCTGGAAGTTGTACTCCCGGAA and 5'-CTACCGCCACGCGTCAGCAAA, respectively, and the probe was $5^{\prime}$-GTCTTTGACCTGGAGGGCATC. For EBNA 1 expression, both the viral Qp (latent) and $\mathrm{Cp} / \mathrm{Wp}$ (lytic) promoters were analysed. To avoid possible contamination, nested PCR was not used. After 39 cycles of amplification, PCR products were separated by electrophoresis on $1 \%$ agarose gels containing ethidium bromide, and their identities were verified by Southern blot hybridisation. For IR4 hybridisation, probes from both C15 and Raji sequences were used (Xue et al, 2000).

\section{Immunohistochemical evaluation of markers on breast cancer tissues}

Antibodies to CD45 (leucocyte common antigen), CD3 (T-cell specific) and CD79a (B-cell specific) (DAKO, Denmark House, Cambridgeshire) were used in tissue examinations. Sections were cut from formalin-fixed, paraffin-embedded blocks and incubated with optimally diluted primary antibody for $60 \mathrm{~min}$, washed $(3 \times)$ with phosphate-buffered saline (PBS), developed using the DAKO Duet/HRP system, and visualised with diaminobenzidine (DAB).

\section{Excision of epithelial cell populations from tumour tissue}

Blocks of frozen tissue from BC 10 and 11, mounted on freezing chucks with OCT (Ames) and sectioned at $4 \mu \mathrm{m}$, were placed on glass slides, stained with haematoxylin and eosin (H \& E), and microscopically inspected for the presence or absence of lymphocytes. Total RNA was isolated from excised sections devoid of lymphocytes and reanalysed by RT - PCR for expression of two EBV genes, EBNA1 and CST/BARTs (Hitt et al, 1989; Smith, 2001).

\section{RESULTS}

\section{Stimulation of growth of human epithelial cells by p31 EBV DNA}

Others have shown that breast cancer-derived cell lines can be infected with EBV (Speck and Longnecker, 2000). We asked whether a subgenomic fragment of EBV DNA (recombinant cosmid p31; Griffin and Karran, 1984) - which stimulates epithelial cells from populations of young New World primate (marmoset) parotid, kidney and nasopharynx tissues to proliferate indefinitely in culture (Griffin and Karran, 1984; Karran et al, 1990; Gao et al, 2002) - will likewise stimulate the growth of human breast-milk epithelial cells (Chang et al, 1982), and whether this property is 


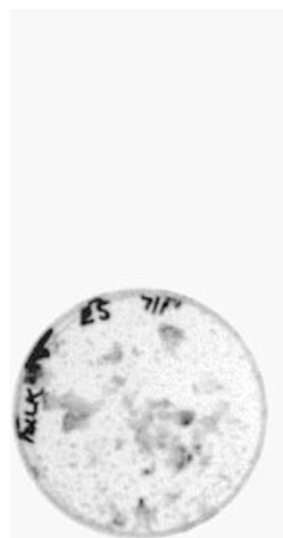

p5

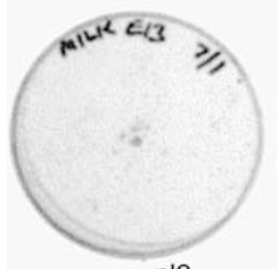

pl3
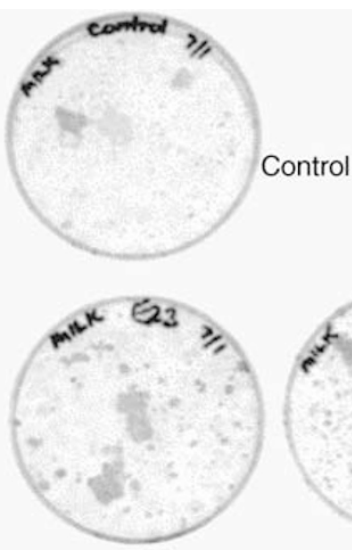

p23

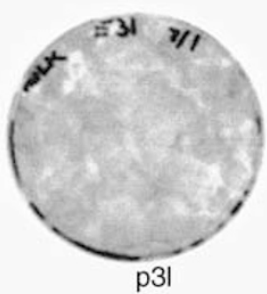

p31

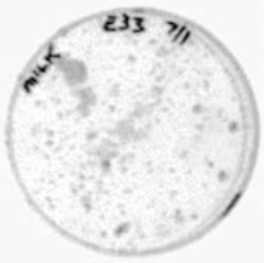

p33

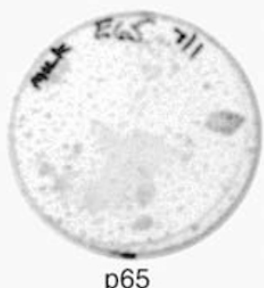

p65
Figure I Growth stimulation of human breast-milk cells by subfragments of EBV DNA from a recombinant cosmid library (Griffin and Karran, 1984), made from a transforming strain of the virus, B95-8. One fragment in particular, p3 I, has the capacity to rescue epithelial cells in primate biopsies from senescence in culture (Griffin and Karran, 1984; Karran et al, 1990; Gao et al, 2002). Cells from long-term milk cultures were visualised with Leishman's stain. Only p3I DNA, among fragments from this library, was found to have the ability to growth stimulate the human epithelial cells, as shown. In other cases, as well as in control untransfected cultures, only small clusters of dead or dying cells were observed with time.

confined to the p31 viral subgenomic fragment. Arguably, if EBV has a role in the genesis and/or growth associated with breast cancer, then growth stimulation in these primary cell cultures might result from their transfection by one or more viral fragments. In this experiment, as shown in Figure 1, only the p31 EBV subfragment was capable of effecting growth stimulation, showing that viral genetic information, which induces survival in other primate epithelial populations, also uniquely stimulates the growth of human milk-derived epithelial cells.

\section{EBV DNA and gene expression in the breast tumours}

Whole-cell DNA taken from the 15 breast carcinoma biopsies, and controls, were examined for the presence of EBV DNA, using as viral marker an early gene, LF3, which contains the repetitive IR4 sequence, and is found expressed in many tumours, including NPCs and Burkitt's lymphomas (BLs) (Xue et al, 2000, 2002). The IR4 repeats are present in high copy numbers (ranging from 22 to 33 ) in different cells and tumours (Xue et al, 2003). By PCR, using 39 cycles of amplification and probes and primers described elsewhere (Xue et al, 2002), this gene was detected in six out of 15 $(40 \%)$ of the breast tumours (BCs $1,4,10-13$ ) examined (data not shown). All but one (BC 4 ) of these tumours were of ductal origin, and BC 4 had ductal components. Only $50 \%$ of the EBV-positive tumours (BC 4,11 and 12) carried ERs. The two lobular tumours among our samples and the other ductal tumours, which included the only two Grade I malignancies investigated, were negative.

For exploring transcriptional expression of viral genes in the EBV-positive malignancies, we focused on the CST/BART, LF3/IR4 and BARF1 genes - since these were often found expressed with high frequency in EBV-associated carcinomas (Hitt et al, 1989; Xue et al, 2000) - and the membrane functions, LMP1 and 2A, expressed in some of these malignancies, as well as the gene for the nuclear antigen, EBNA1, essential for the maintenance of EBV in cells (IARC, 1997), but expressed at low levels. Expression of other viral genes, including the small RNAs (EBERs), often observed in high copy numbers and argued to be diagnostically indicative of EBV (Brink et al, 2000) - but not found so in other cases (Takeuchi et al, 1997; Sugawara et al, 1999) - and BZLF1, BHRF1 and BHLF1/IR2 (see legend to Figure 2), were also explored. None of these gene transcripts (except the EBERs) has been widely used in previous studies investigating EBV in breast cancers, but from recent data on other tumours (IARC, 1997; Sugawara et al 1999; Xue et al, 2000, 2002; Zur Hausen et al, 2000) seemed potentially appropriate for this purpose.

All the EBV-positive breast cancers (BCs 1, 4, 10-13) were found to express the CST/BART and LF3/IR4 transcripts (using protocols that allow for sequence variations, as described in Xue et al, 2000), and three out of six expressed BARF1. EBNA1 expression was found in the same three out of six tumours; very low level gene expression, as indicated by work on NPCs (Hitt et al, 1989), probably accounts for the fact that EBNA1, and possibly BARF1, was not detected in all the tumours. Notably, no expression of EBERs1 or 2, nor the other viral gene transcripts analysed, LMP1/2A, BHLF1/IR2 and BHRF1, was identified in any of these tumours, nor in BC 14, an EBV-positive HD. EBER2 expression was observed, however, in the cervical lymphadenopathy, BC 9, and expression of other viral genes, such as EBER1 and LMP1, was identified in control cells (not shown), indicating that negative data in the breast cancers did not reflect methodology problems. BZLF1 was found in one malignancy (BC 12), which was infiltrated with both T- and B lymphocytes (see below). Data from some of our studies are summarised in a combined Figure 2, and in Table 1.

When viral gene and ER expression data were compared, there was no correlation, ruling out hormonal control over EBV expression in these tumours.

\section{Analysis of invasive lymphocytes in the breast tumour biopsies}

It has been argued by some that invasive, virally infected B lymphocytes might explain the presence of EBV in breast cancers (Brink et al, 2000; Chu et al, 2001; McCall et al, 2001). For this reason, in our molecular analyses (cited above), we largely focused on viral genes associated with EBV-positive carcinomas, rather than those drawn from the literature on B cells (summarised in IARC, 1997). In addition, for reasons of interest and possible relevance, we examined the status of the EBV-positive tumours with regard to invasive lymphocytes. Cell morphology in paraffinfixed EBV-positive breast cancer sections, BCs 1, 4, 10-13, was examined by $\mathrm{H}$ \& $\mathrm{E}$ staining, with lymphocyte populations detected using the leuckocyte common antibody, CD45. In this study, few if any lymphocytes were observed in the tumour population in $\mathrm{BC} 10$, whereas in $\mathrm{BCs} 1,4,11$ and 13 occasional lymphoid aggregates, located mainly on the periphery of the tumours, were observed. An interesting exception was found in $\mathrm{BC}$ 12 , where heavy lymphoid infiltration was observed in the tumour.

Further, staining studies were carried out on sections to identify the nature of the lymphocytes, using monoclonal antibodies CD79a and $\mathrm{CD} 3$ to stain B- and T-lymphocyte populations, respectively. Again, little or no staining was seen in the epithelial cells in BC 10, using either antibody (not shown), although occasional staining cells were observed in the stroma (as indicated in Figure 3A, middle panel at left). In most of the other tumours, except BC 12, staining showed invasive lymphocyte populations to be mainly of T-cell origin $\left(\mathrm{CD}^{+} / \mathrm{CD} 7 \mathrm{a}^{-}\right)$(not given). In $\mathrm{BC} 11$, one patch of intratumour B cells $\left(\mathrm{CD} 7 \mathrm{a}^{+}\right)$, as shown (Figure $3 \mathrm{~A}$, middle panel 


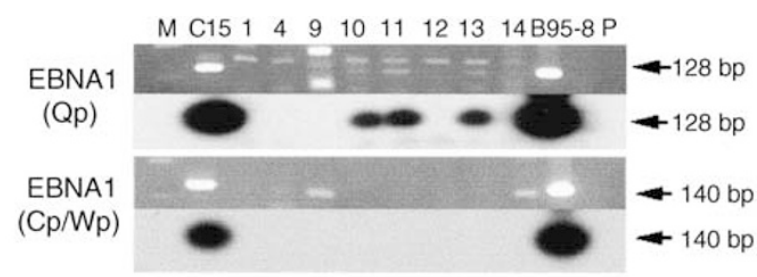

\begin{tabular}{lllllllll}
$M$ & 1 & 4 & 9 & 10 & 11 & 12 & 13 & 14 \\
\hline
\end{tabular}

CST

(BART)

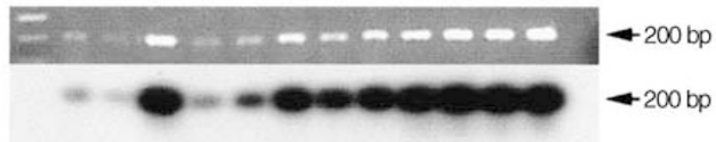

$\begin{array}{lllllllll}M & 1 & 4 & 9 & 10 & 11 & 12 & 13 & 14 \text { NPC BLC15B95-8 P }\end{array}$
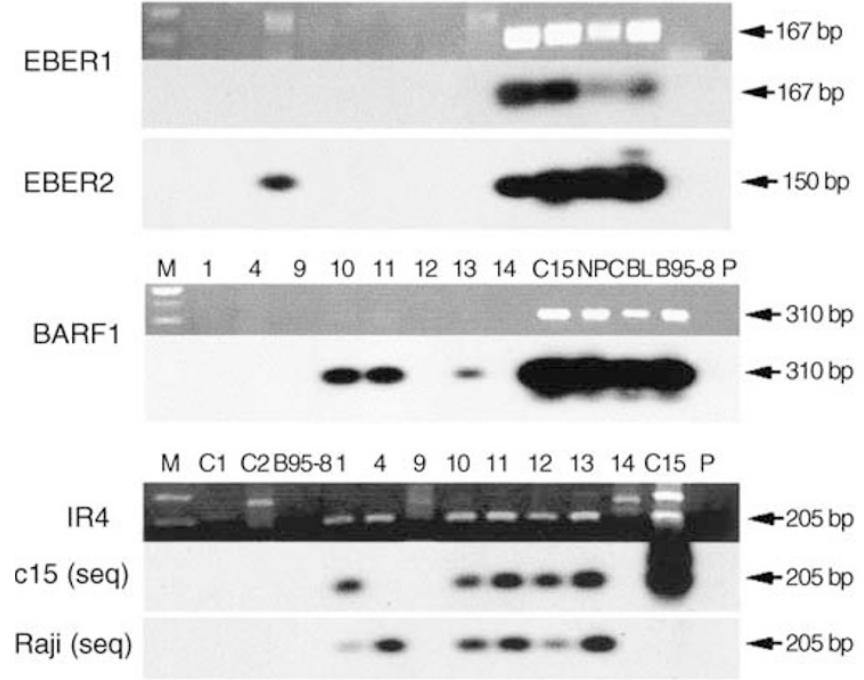

$\begin{array}{llllllllllll}\text { M } & \text { C1 C2 Daudi } 14 & 4 & 9 & 10 & 11 & 12 & 13 & 14 & \text { C15 P }\end{array}$

IR2

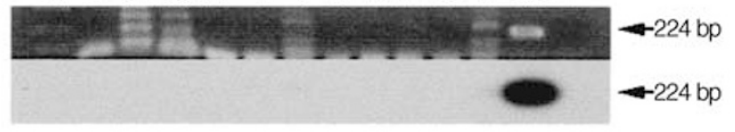

$\begin{array}{lllllllll}M & 1 & 4 & 9 & 10 & 11 & 1213 & 14 & \text { P3HR1P }\end{array}$

BZLF1

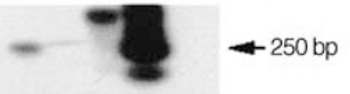

Figure 2 Analysis of expression of EBV RNA in viral DNA-positive breast cancer biopsies (BCs |, 4, |0- |3). EBV genes whose transcriptional expression was monitored include: EBNAI, an essential gene for viral maintenance; three genes (CST/BART, LF3/IR4 and BARFI) expressed in other epithelial cell malignancies (Hitt et al, 1989; Xue et al, 2000, 2002); small viral RNAs (EBERs I and 2) of unknown function but frequently expressed in EBV-associated tumours (Arrand, 2000); BZLFI, an intermediate-early viral lytic cycle marker; and BHLFI/IR2, not universally found in carcinomas but often highly expressed in B-cell lymphomas (Xue et al, 2000). Also analysed, but found negative (and not shown), are viral membrane proteins, $L M P I$ and $2 \mathrm{~A}$, associated with growth of $B$ cells, and BHRFI, a viral homologue of $B C l-2$ (see IARC, 1997). Biopsies, BCs I, 4, $10-13$, are EBV-positive breast cancers, and, except for BC 4, mostly of ductal origin; BC 9 was from a cervical lymphadenopathy, clinically questioned as 'possibly of viral origin'; and BC 14 from an HD. For the latter two cases, the original designation $\mathrm{BC}$ is retained here, although these were subsequently shown not to be breast carcinomas. Other controls include NPCs (both of Asian and North African origin) and a xenograft (CI5; see Table I), a Malawian Burkitt's lymphoma (BL) and B95-8, a prototype strain from a mononucleosis patient. In the EBNA I assays, expressions from both latent $(\mathrm{Qp})$ and lytic $(\mathrm{Cp} / \mathrm{Wp})$ promoters were analysed. For IR4/LF3 hybridisation, probes corresponding to sequences in $\mathrm{Cl} 5$ and Raji were used (Xue et al, 2000). Tracks M contain molecular weight markers. at right), was observed. $\mathrm{BC} 12$, on the other hand, differed from the other tumours in containing large numbers of lymphocytes (see Figure $3 \mathrm{~B}, \mathrm{H} \& \mathrm{E}$ staining). Most of these were $\mathrm{T}$ cells, as shown in Figure $3 \mathrm{~B}\left(\mathrm{CD}^{+}\right.$, at right), although about $5 \%$ of them stained with the B-cell (CD79a) marker (not shown).

\section{EBV gene expression in excised epithelial cells}

To refute further the arguments that EBV in human breast cancer materials merely reflects the possible presence of EBV-positive B cells in the tumour, we re-examined the status of fresh frozen samples of BC 10 and 11. First, these were subsectioned and stained with the relevant antibodies to B- and T-lymphocytes, as described above. Then, sections where staining showed no or negligible lymphocyte components were excised (as illustrated in Figure $3 \mathrm{~A}$, bottom panel at left) and used to make fresh RNA. If invasive lymphocytes had been the source of the EBV gene expression pattern we previously observed (Figure 2), then quantitatively the load should be diminished or abolished by their removal. On re-examining expression of CST/BARTs and EBNA1 in these tumours (Figure 4), however, the data showed that little or no differences were observed in gene expression between selected samples and total biopsy (Figure 2) samples, arguing for the presence of EBV in the tumour cells themselves.

\section{Role of amplification in the detection of EBV gene expression}

In one PCR study (McCall et al, 2001), the importance of amplification cycles was suggested to be of possible significance for the detection of EBV in breast cancers. Our data imply that use of fresh, rather than fixed, sample materials is also a critical factor, as is the choice of viral genes for analysis. We examined viral load in different samples by semiquantitative RT - PCR as a contributing factor in detection, using the CST/BART transcripts observed in all the tumour materials as a marker. For this study, we chose two breast tumours with different levels of expression, BC 1 (weak) and BC 12 (strong) (Figure 2), and the lymphadenopathy (BC 9) and $\mathrm{C} 15$ tumour (both very strong) as controls. Using the same primers as elsewhere (Figures 2), and scoring as positive band detection by ethidium bromide staining (as in Figure 2) after 30 cycles of amplification, expression was detectable in controls only; at 35 cycles, BC 12 was positive; at 40 cycles, expression was also observed in $\mathrm{BC}$. These data (not given) emphasise the low levels of gene expression in EBV-positive breast tumours in general, and in some in particular, but do not distinguish among high viral loads in a few cells only, or very low levels in many. They confirm the arguments about loads put forward elsewhere (McCall et al, 2001).

\section{DISCUSSION}

The herpesvirus EBV, a causative agent for infectious mononucleosis, has been associated with various malignancies with frequencies that vary from $100 \%$ (in poorly differentiated NPC) to a few percent only (in adenocarcinomas) (IARC, 1997), or, as recently discussed, up to $45 \%$ (nine out of 20 ) in fibroadenomas from HIV-positive individuals (Kleer et al, 2002). In some studies, EBV has been identified as a component of breast cancers (Labrecque et al, 1995; Luqmani and Shousha, 1995; Bonnet et al, 1999; Fina et al, 2001; Grinstein et al, 2002; Kleer et al, 2002) in up to $50 \%$ of cases examined (Bonnet et al, 1999). Interestingly, whereas association of EBV with about $10 \%$ of human gastric carcinomas (Shibata and Weiss, 1992; Rowlands et al, 1993; Galetsky et al, 1997; Takano et al, 1999; Yoshiyama et al, 1997; Zur Hausen et al, 2000) is accepted as real and meaningful, the association of this virus with human breast cancer 
Table I EBV gene expression in breast cancer and controls

\begin{tabular}{lcccccccccc}
\hline & \multicolumn{10}{c}{ Breast samples } \\
\cline { 2 - 10 } EBV genes & BC I & BC 4 & BC I0 & BC I I & BC I2 & BC I3 & $\mathbf{9}$ & I4 & C I5 \\
\hline BZLFI & - & - & - & - & + & - & - & & - & + \\
CST (BART) & + & + & + & + & + & + & + & + & + \\
IR4/LF3 (Raji seq) & + & + & + & + & + & + & - & - & - \\
IR4/LF3 (Cl5 seq) & + & - & + & + & + & + & - & - & + \\
EBNAI (Qp) & - & - & + & + & - & + & - & - & + \\
EBER2 & - & - & - & - & - & - & + & - & +
\end{tabular}

Negative in breast cancers: EBERI, EBNAI (Cp/WP), BHRFI, IR2/BHLFI, LMPI, LMP2A. BC I = NHS BSP grade II ducta carcinoma; BC 4=mixed pattern carcinoma, ductal elements present; BC $10=$ high-grade ductal carcinoma; $B C$ I I = ductal carcinoma; BC 12 =NHS BSP grade II infiltrating ductal carcinoma; BC I $3=$ NHS BSP grade II invasive ductal carcinoma; 9 = cervical lymph node; 14=HD; CI5=NPC xenograft (Busson et al, 1988).

remains controversial in spite of the well-documented positive findings, and higher frequencies (reviewed by Magrath and Bhatia, 1999).

Here we have explored the hypothesis that in studies where EBV has not been identified in breast cancers, either in terms of its genome or expressed genes, experimental design - which may fail to allow for low viral loads, or rely on the expression of EBV gene patterns more appropriately associated with B-cell malignancies may be a key factor (Brink et al, 2000; Chu et al, 1998; McCall et al, 2001). Further, the use of fixed archival samples by some investigators (Gaffey et al, 1993; Horiuchi et al, 1994; Lespagnard et al, 1995; Chu et al, 1998, 2001; Glaser et al, 1998), rather than fresh materials, can compound the problem as recovery of nucleic acids from such materials may be hampered, and fixation can result in DNA (mutational) damage (Williams et al, 1999). From the data, it is not clear, moreover, that the small viral RNAs (EBERs) need be good markers for EBV in this malignancy (Bonnet et al, 1999), and several studies have relied heavily on them to define the presence or absence of EBV in breast samples (Horiuchi et al, 1994; Glaser et al, 1998; Brink et al, 2000). Moreover, a further factor may account for some discrepancy in that different histological variants of this malignancy may vary in their association with EBV. It is notable and of possible relevance that in two studies on medullary carcinomas, which share many characteristics of lymphoepithelomas and among the breast cancers have a generally better prognosis, EBV was not identified (Gaffey et al 1993; Lespagnard et al 1995). However, these data were not consistent with that reported elsewhere (Luqmani and Shousha, 1995). Perhaps, more than anything else, the data on EBV in breast cancer argue strongly for a larger scale and more systematic study of this topic than, with one possible exception (Fina et al, 2001), has been carried out to date.

In our current studies, we have used well-defined fresh biopsy materials, and focused mainly on viral genes that appear from other work (Griffin and Karran, 1984; Hitt et al, 1989; Karran et al, 1990; Zur Hausen et al, 2000; Gao et al, 2002) to have relevance for epithelial cells. We initiated our work by identifying the ability of one subfragment of EBV DNA (p31), but not others, to stimulate the growth of human milk epithelial cells in culture (Figure 1). Then, using two viral genes (CST/BARTs and BARF1) found within p31 DNA, another (LF3) from the same region of the genome that has been found expressed in all EBV-associated tumours where it has been explored to date (Xue et al, 2000; 2003), and the EBNA1 gene required for maintenance of EBV, and others, we made a detailed investigation of a sample of British breast cancer patients. The samples were fresh and all came from patients seen in a single hospital within a short period of time. All were treated by mastectomy, and most were of Caucasian origin with ductal carcinomas. In all, $40 \%$ (six out of 15) of these were found to carry the EBV genome and express viral genes. With four viral genes (CST/BARTs and LF3/IR4 (six out of six positive), and EBNA1 and
BARF1 (three out of six), the data were incontrovertible - although one would predict that EBNA1 at least is probably expressed in all these tumours, but below the level of our detection methods. As in some other cases of carcinoma (Takeuchi et al, 1997; Sugawara et al, 1999; reviewed by Arrand, 2000), the small viral RNAs, EBERs, which provide good markers for analysing EBV association in some other tumours, proved not equally useful for the breast samples. In some cases, particularly for example that of the tumour BC 10, with no lymphocyte infiltrates, other viral genes but not EBERs were expressed. Our data on viral gene expression are shown in part in Figures 2 and 4, and summarised in Table 1. Data on lymphocyte infiltration into the tumour populations are given in Figure 3. We found that in the positive breast samples from a British population, even in fresh biopsies, EBV expression levels were low as compared, for example, with those found in Asian NPCs or African BLs, and required optimisation of techniques for detection.

In general, the EBV-positive cases were younger (median age 54 years) than their EBV-negative (median age 63 years) counterparts. In particular, we draw attention to the case of patient BC 12 (aged 33 years), whose tumour was unique among those examined, both with regard to its viral gene expression pattern and its intense chronic inflammatory infiltrate. Adjacent normal breast lobules also showed a similar inflammatory infiltrate, clinically suggestive of an enhanced host response. Alone among the breast tumours studied, BC 12 expressed a transcription product associated with the active spliced version (Figure 2) of one of the intermediateearly viral genes, BZLF1 (or ZEBRA), that disrupts EBV latency (Miller, 1990). In the HD, BC 14, studied as a control, a product possibly from an unspliced transcript of this gene was expressed. Although it has been suggested that only $\mathrm{T}$ lymphocytes invade epithelial cells (Hayday et al, 2001), and our histology studies showed that any B cells associated with the breast tumour populations under investigation lay mainly at their periphery, uniquely in BC 12 many infiltrates were observed in the tumour. Although these were mainly $\mathrm{T}$ lymphocytes (Figure 3B), there were $\mathrm{B}$ cells among them. Thus, the BZLF1 expression detected in this particular tumour could have been a product of the invasive lymphocytes, which in turn provoked an enhanced host response in the patient. Arguably, as shown recently (Speck and Longnecker, 2000), EBV-infected lymphocytes may be uniquely capable of targeting breast epithelial cells. Assuming tumours such as BC 12 to make up a subclass of breast cancers, it would be of therapeutic relevance to explore whether harbouring a potentially oncolytic version of EBV can be put to therapeutic use, as discussed for other viruses (Chiocca, 2002). Of possible relevance to this suggestion, introduction of the BZLF1 (or a similar EBV gene) via an adenoviral vector was shown to inhibit the growth of an NPC xenograft in a mouse model (Feng et al, 2002). Harnessing endogenous EBV gene expression for therapeutically useful purposes may thus be worthy of further exploration. 
A $\quad B C-10 H \& E$ staining

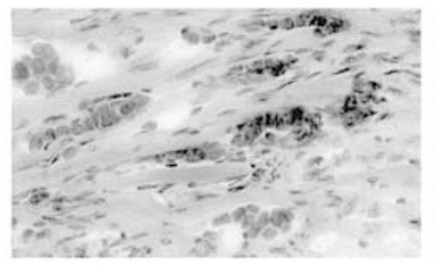

BC-10 CD79a staining

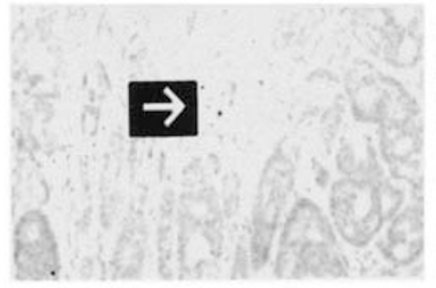

BC-10 tumour excision

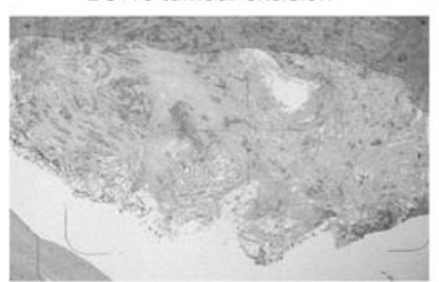

B

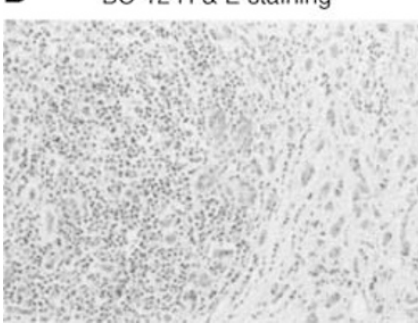

$\mathrm{BC}-11 \mathrm{H}$ \& E staining

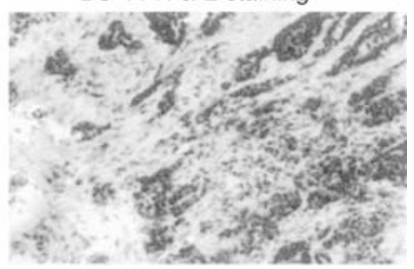

BC-11 CD79a staining

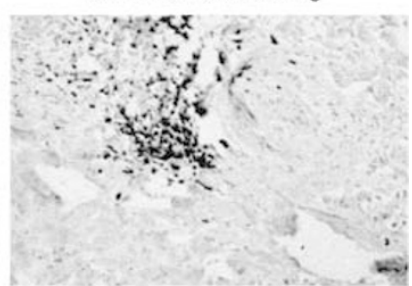

BC-11 CD3 staining

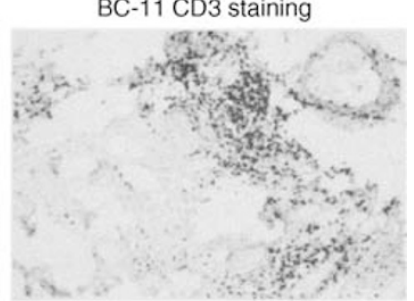

BC-12 CD3 staining

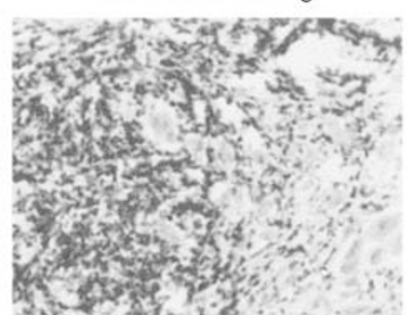

Figure 3 Histology of variants of EBV-positive ductal carcinoma biopsies (BCs I0, II and 12). (Magnification $\times 200$ ). (A) Panels (at top) show H \& $\mathrm{E}$ (dark) staining of paraffin-embedded, frozen sections of $\mathrm{BC} 10$, and $\mathrm{BC}$ II. Section were also stained using antibodies CD79a (for B lymphocytes) and CD3 (for T lymphocytes), as noted. No lymphocyte staining was observed in the tumour population in $\mathrm{BC} 10$, as confirmed by laser dissection microscopy (by Dr B Terris). Any lymphocyte staining in BC 10 was confined to the stroma, as indicated (arrow, middle panel on left), whereas in BC 11 , a single patch comprising $<5 \%$ of the tumour population stained positive with CD 79a (middle panel on right), although most of the lymphocytes within the tumour stained with the T-cell marker (bottom panel on right). Sections free of stroma-containing lymphocytes in BC IO, as illustrated, or freed of B cells in BC I I by dissection (not shown) were subjected to a separate round of RT-PCR analysis (see Figure 4). (B) $\mathrm{BC}$ I2, a tumour with inflammatory cells, was stained by $\mathrm{H}$ \& $\mathrm{E}$ (at left), with CD3 (at right) and with CD79a (not shown). This tumour, as shown on the left panel, was heavily infiltrated by lymphocytes, the large majority (about 95\%) of which proved on staining to be T cells, as shown (on right). Some CD79a-staining cells within the tumour were observed.

From accumulating data in the literature (see above) and those presented here, we argue that the relevant question(s) now is not whether EBV can be present and persist in breast carcinomas, but rather what its role might be. The notion of this virus as a

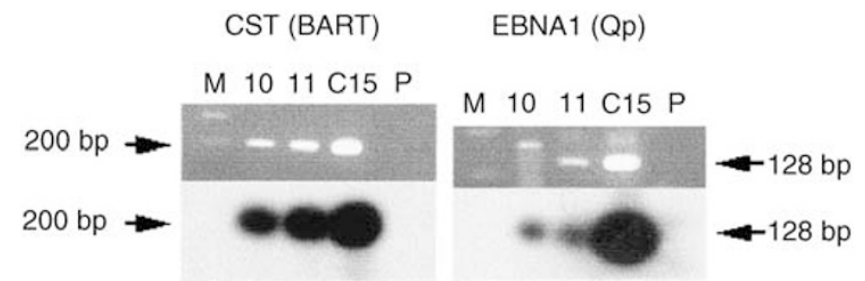

Figure 4 RT-PCR results on $B C s 10$ and $I I$, after selection for lymphocyte-deficient epithelial sections (see Figure 3). EBV gene expression (CST/BART and EBNAI, as noted; see also Figure 2) was reinvestigated on RNA isolated from sections with negligible invasive lymphocytes. Primers used for amplification and probes are the same as in Figure 2. RNA from the NPC xenograft CI 5 (with 30 copies of EBV DNA; Busson et al, 1988) was used as positive control and primers only $(P)$ as a negative control. Track (M) contained 100 bp DNA ladders (Promega).

'harmless' passenger' (Labrecque et al, 1995) seems implausible in view of its association with many malignancies of different cell types, and the ability of its genes to contribute to cellular growth (immortalisation) in culture. In a recent comprehensive study of EBV, it was declared to be 'carcinogenic to humans' (IARC, 1997). Bonnet et al (1999) showed that the more aggressive breast tumours in their studies were to be found among the EBV-positive cases. Our data were mainly derived from grade II/III breast malignancies that were evenly split with regard to their EBV status, whereas neither of the grade I malignancies available for study proved to be EBV positive. One of the functions that EBV can confer upon epithelial cells is to extend their life span, as illustrated in Figure 1 and elsewhere. In other studies, primary epithelial cells immortalised by a subfragment of EBV appeared to lose their viral information (classically called 'hit and run' immortalisation), yet did not go through crisis; throughout their growth cycle their telomeres remained constant in length (Gao et al, 2002). In recent studies on gastric carcinoma cell lines (Kassis et al, 2002), the presence of EBV was found to increase cell motility and mobility. The data overall argue for EBV as a protagonist with regard to some carcinomas, including breast cancer, possibly acting as a 'carcinogenic agent' that can maintain telomerase activity in vivo. The virus seems unlikely to be a mere passenger.

In the newer molecular approaches, transcription profiles and microarray techniques are being used to modify taxonomies for breast cancer. For example, Perou et al (2000), using 65 different surgically removed samples identified great variations in the patterns of gene expression, with sets of genes (clusters) contributing to independent patterns. The largest cluster included expression of genes associated with cellular proliferation. Oestrogen receptors were also detected in a cluster. Microarray technology offers great potential for unravelling some of the problems associated with breast cancer. In future, it would seem relevant to adapt it to include EBV gene expression.

\section{ACKNOWLEDGEMENTS}

We thank Dr B Terris (ICRF Unit, Hammersmith Hospital) for confirming the lymphocyte status of tumours BC 10 and 11 and $\mathrm{Mr}$ Daniel Hollyman for technical help. We wish to dedicate this paper to the memory of Dr Stuart Haldane, who died tragically during the course of our study.

\section{REFERENCES}

Arrand JR (2000) Expressed But Enigmatic RNAs, Epstein-Barr virus reports, Vol. 7, pp 145-149

Bayliss GJ, Wolf H (1980) Epstein-Barr-virus-induced cell fusion. Nature 287: $164-165$ 
Bonnet M, Guinebretiere JM, Kremmer E, Grunewald V, Benhamou E, Contesso G, Joab I (1999) Detection of Epstein-Barr virus in invasive breast cancer. J Natl Cancer Inst 91: 1376-1381

Brink AATP, van den Brule AJC, van Diest P, Meijer JLM (2000) EpsteinBarr virus and breast cancer. J Natl Cancer Inst 92: 655

Busson P, Ganem G, Flores P, Mugneret F, Clausse B, Caillou B, Braham K, Wakasugi H, Lipinski M, Tursz T (1988) Establishment and characterisation of three transplantable EBV-containing nasopharyngeal carcinomas. Int J Cancer 42: 599-606

Chang SE, Keen J, Lane EB, Taylor-Papadimitriou J (1982) Establishment and characterization of SV40-transformed human breast epithelial cell lines. Cancer Res 42: 2040-2053

Chiocca EA (2002) Oncolytic viruses. Nat Rev Cancer 2: $938-950$

Chu J-S, Chen C-C, Chang K-J (1998) In situ detection of Epstein-Barr virus in breast cancer. Cancer Lett 124: 53-57

Chu PG, Chang KL, Chen Y-Y, Chen W-G, Weiss LM (2001) No significant association of Epstein-Barr virus infection with invasive breast carcinoma. Am J Pathol 159: 571-578

Feng WH, Westphal E, Mauser A, Raab-Traub N, Gulley ML, Busson P, Kenney SC (2002) Use of adenovirus vectors expressing Epstein-Barr virus (EBV) immediate-early protein BZLF1 or BRLF1 to treat EBVpositive tumors. J Virol 76: $10951-10959$

Fina F, Romain S, Ouafik L'H, Palmari J, Ben-Ayed F, Benharkat S, Bonnier P, Spyratos F, Foekens JA, Rose C, Buisson M, Gerard H, Reymond MO, Seigneurin JM, Martin PM (2001) Frequency and genome load of Epstein-Barr virus in 509 breast cancers from different geographical areas. $\mathrm{Br}$ J Cancer 84: $783-790$

Gaffey MJ, Frierson Jr HF, Mills SE, Zarbo RJ, Boyd JC, Simpson JF, Weiss LM (1993) Medullary carcinoma of the breast. Identification of lymphocyte subpopulations and their significance. Mod Pathol 6: 721 728

Galetsky SA, Tsvetnov VV, Land CE, Afanasieva TA, Petrovichev NN, Gurtsevitch VE, Tokunaga M (1997) Epstein-Barr virus-associated gastric cancer in Russia. Int J Cancer 73: 786-789

Gao Y, Lu Y-J, Xue S-A, Chen H, Wedderburn N, Griffin BE (2002) Hypothesis: a novel route for immortalization of epithelial cells by Epstein - Barr virus. Oncogene 21: 825-835

Glaser SL, Ambinder RF, DiGiuseppe JA, Hornross PL, Hsu JL (1998) Absence of Epstein-Barr virus EBER-1 transcripts in an epidemiologically diverse groups of breast cancers. Int $J$ Cancer 75: $555-558$

Griffin BE, Karran L (1984) Immortalization of monkey epithelial cells by specific fragments of Epstein - Barr virus DNA. Nature 309: 78-82

Grinstein S, Preciado MV, Gattuso P, Chabay PA, Warren WH, De Matteo E, Gould VE (2002) Demonstration of Epstein - Barr virus in carcinomas of various sites. Cancer Res 62: $4876-4878$

Hayday A, Theodoridis E, Ramsburg E, Shires J (2001) Intraepithelial lymphocytes: exploring the Third Way in immunology. Nat Immunol 2: $997-1003$

Hitt MM, Allday MJ, Hara T, Karran L, Jones MD, Busson P, Tursz T, Ernberg I, Griffin BE (1989) EBV gene expression in an NPC-related tumour . EMBO J 8: 2639-2651

Horiuchi K, Mishima K, Ohsawa M, Aozasa K (1994) Carcinoma of stomach and breast with lymphoid stroma: localisation of Epstein-Barr virus. J Clin Pathol 47: 538-540

IARC Monograph (1997) Epstein-Barr Virus and Kaposi's Sarcoma Herpesvirus/Human Herpesvirus 8. Vol. 70, pp 47-373. Lyon: IARC Press

Joab I (2000) Detection of Epstein - Barr virus in invasive breast cancers. J Natl Cancer Inst 92: 656

Karran L, Teo CG, King D, Hitt MM, Gao Y, Wedderburn N, Griffin BE (1990) Establishment of immortalized primate epithelial cells with subgenomic EBV DNA. Int J Cancer 45: 763-772

Kassis J, Maeda A, Teramoto N, Takada K, Wu C, Klein G, Wells A (2002) EBV-expressing AGS gastric carcinoma cell sublines present increased motility and invasiveness. Int J Cancer 99: 644-651

Kleer CG, Tseng MD, Gutsch DE, Rochford RA, Wu A, Joynt LK, Helvie MA, Chang R, van Golen KL, Merajvery S (2002) Detection of Epstein Barr virus in rapidly growing fibroadenomas of the breast in immunosuppressed hosts. Mod Pathol 15: 759-764

Labrecque LG, Barnes DM, Fentiman IS, Griffin BE (1995) Epstein-Barr virus in epithelial cell tumors: A breast cancer study. Cancer Res 55: $39-45$

Lespagnard L, Cochaux P, Larsimont D, Degeyter M, Velu T, Heimann R (1995) Absence of Epstein-Barr virus in medullary carcinoma of the breast as demonstrated by immunophenotyping, in situ hybridization and polymerase chain reaction. Am J Clin Pathol 103: 449-452

Luqmani YA, Shousha S (1995) Presence of Epstein-Barr virus in breast carcinoma. Int J Oncol 6: 899-903

Magrath I, Bhatia K (1999) Breast cancer: a new Epstein-Barr virusassociated disease? J Natl Cancer Inst 91: 1349-1350

Masood S, Kameh D (2002) Breast. In: The Cancer Handbook, Alison MR (ed.-in-chief) Vol. 1, pp 611-616. London: Nature Pub Group, Macmillan Publishers Ltd

McCall SA, Lichy JH, Bijwaard KE, Aguilera NS, Chu WS, Taubenberger JK (2001) Epstein-Barr Virus only rarely detected in ductal carcinoma of the breast. J Natl Cancer Inst 93: $148-150$

Miller G (1990) The switch between latency and replication of Epstein - Barr virus. J Inf Dis 161: $833-844$

Parkin DM, Pisani P, Ferlay J (1999) Global cancer statistics. CA Cancer J Clin 49: $33-64$

Perou CM, Sorlie T, Elsen MB, van de Rijn M, Jeffrey SS, Rees CA, Pollack JR, Ross DT, Johnsen H, Akslen LA, Fluge O, Pergamenschikov A, Williams C, Zhu SX, Lonning PE, Borresen-Dale AL, Brown PO, Botstein D (2000) Molecular portraits of human breast tumours. Nature 406: $747-752$

Richardson A (1997) Is breast cancer caused by late exposure to a common virus? Med Hypotheses 48: $491-497$

Rowlands DC, Ito M, Mangham DC, Reynolds G, Herbst H, Hallissey MT, Fielding JW, Newbold KM, Jones EL, Young LS, Niedobitek G (1993) Epstein-Barr virus and carcinomas: rare association of the virus with gastric adenocarcinomas. Br J Cancer 68: 1014-1019

Shibata D, Weiss LM (1992) Epstein-Barr virus-associated gastric adenocarcinoma. Am J Pathol 140: $769-774$

Sixbey JW, Davis DS, Young LS, Hutt-Fletcher L, Tedder TF, Rickinson AB (1987) Human epithelial cell expression of an Epstein-Barr virus receptor. J gen Virol 68: $805-811$

Smith P (2001) Epstein-Barr virus complementary strand transcripts (CSTs/BARTs) and cancer. Semin Cancer Biol 11: 469-476

Speck P, Longnecker R (2000) Infection of breast epithelial cells with Epstein - Barr virus via cell-to-cell contact. J Natl Cancer Inst 92: 1849 1851

Strockbine LD, Cohen JI, Farrah T, Lyman SD, Wagener F, DuBose RF, Armitage RF, Spriggs MK (1998) The Epstein-Barr virus BARF1 gene encodes a novel, soluble colony-stimulating factor-1 receptor. J Virol 72: $4015-4021$

Sugawara Y, Mizugaki Y, Uchida T, Torii T, Imai S, Makuuchi M, Takada K (1999) Detection of Epstein-Barr virus (EBV) in hepatocellular carcinoma tissue A novel EBV latency characterized by the absence of EBV-encoded small RNA expression. Virology 256: 196-202

Takano Y, Kato Y, Saegusa M, Mori S, Shiota M, Masuda M, Mikami T, Okayasu I (1999) The role of the Epstein - Barr virus in the oncogenesis of EBV (+) gastric carcinomas. Virch Arch 434: 17-22

Takeuchi H, Kobayashi R, Hasagawa M, Hirai K (1997) Detection of latent Epstein-Barr virus (EBV) in paraffin sections of nasopharyngeal carcinomas expressing no EBV-encoded small RNAs using in situ PCR. Arch Virol 42: $1743-1756$

Williams C, Pontén F, Moberg C, Soderkvist P, Uhlen M, Pontén J, Sitbon G, Lundeberg J (1999) A high frequency of sequence alterations is due to formalin fixation of archival specimens. Am J Pathol 155: 1467-1471

Xue S-A, Jones MD, Lu Q-L, Middeldorp JM, Griffin BE (2003) Genetic diversity: Frameshift mechanisms alter coding of a gene (Epstein-Barr virus LF3) that contains multiple $102 \mathrm{bp}$ direct sequence repeats. Mol. Cell. Biol. 23: $2192-2201$

Xue S-A, Labrecque LG, Lu Q-L, Ong SK, Lampert IA, Kazembe P, Molyneux E, Broadhead RL, Borgstein E, Griffin BE (2002) Promiscuous expression of Epstein - Barr virus genes in Burkitt's lymphoma from the central African country Malawi. Int J Cancer 99: 635-643

Xue S-A, Lu Q-L, Poulsom R, Karran L, Jones MD, Griffin BE (2000) Expression of two related viral early genes in Epstein-Barr virusassociated tumor. J Virol 74: 2793-2803

Yasui Y, Potter JD, Stanford JL, Rossing MA, Winget MD, Bronner M, Daling J (2001) Breast cancer risk and 'delayed' primary Epstein - Barr virus infection. Cancer Epidemiol Biomarkers Prev 10: 9-16

Yoshiyama H, Imai S, Shimizu N, Takada K (1997) Epstein-Barr virus infection of human gastric carcinoma cells: implication of the existence of a new virus receptor different from CD21. J Virol 71: 5688-5691

Zur Hausen A, Brink AA, Craanen ME, Middeldorp JM, Meijer CJ, van den Brule AJ (2000) Unique transcription pattern of Epstein-Barr virus $(\mathrm{EBV})$ in EBV-carrying gastric adenocarcinomas: expression of the transforming BARF1 gene. Cancer Res 60: 2745-2757 